\title{
Seizing the "Both/And" Moment
}

\author{
Becky Marsh, Adrienne Rodriguez, Amy Lewis, Latasha Thomas- \\ Durrell, and Juliet Hess \\ Michigan State University, USA
}

In Remixing the Classroom: Toward an Open Philosophy of Music Education (2016), Randall Allsup expresses a sincere longing for an open approach to music education, rooted in exploration, creation, and student agency. Allsup's philosophy centers on the distinction between open and closed forms, the latter of which he describes as the dominant form, and he explicitly calls for a transformation of music education. Though he makes several clear assertions regarding the need for both open and closed forms, Allsup often implicitly advocates for abandoning closed forms, describing their practices as oppressive. In this paper, the authors draw upon Jorgensen's (2003) images of transformation to consider Allsup's call to action, highlighting the contradictory nature of his argument and providing vignettes from their personal experiences as music educators to illustrate their belief that both closed and open forms are essential for the transformation of music education.

Keywords: music education, transformation, philosophy, pedagogy, music teacher education, Allsup

$\mathrm{I}$ n Remixing the Classroom: Toward an Open Philosophy of Music Education (2016), Randall Allsup expresses a sincere longing for an open approach to music education, rooted in exploration, creation, and student agency. The teacher who embraces open forms is one who acts as a fellow adventurer alongside their students and who celebrates diversity, in its many forms, in their classroom. Allsup describes a sharp contrast between his vision of an open philosophy of music education and the long-held closed, Master-apprentice model for music teaching with heavy reliance on the teaching of previously

(C) Becky Marsh, Adrienne Rodriguez, Amy Lewis, Latasha Thomas-Durrell, and Juliet Hess 2017. The content of this article is the sole responsibility of the author. The ACT Journal and the Mayday Group are not liable for any legal actions that may arise involving the article's content, including, but not limited to, copyright infringement. 
established Western classical music skills, techniques, and norms-a model of teaching continually implemented by institutions of higher education as the standard for music education (Koza 2008; Nettl 1994). Remixing the Classroom provides inspiration and provocation to consider how we, as music teachers and music teacher educators, might break the cycle of exclusivity that pervades much of public school music education today. Allsup explicitly calls for a transformation of music education. In this paper, we draw upon Jorgensen's (2003) images of transformation to consider Allsup's call to action. We assert that Allsup's proposed transformation aligns with Jorgensen's notion of transformation through inversion. We push instead toward a model of transformation that we find more productive-a transformation through integration (Jorgensen 2003).

This review began as a class discussion between the authors in an advanced philosophy of music education course after reading the first chapter of Remixing the Classroom (2016). We were excited about the possibilities and ramifications for music education presented and opted to read the remainder of the book, which resulted in rich discussions about the future of music education in both collegiate and $\mathrm{P}-12$ settings. We collectively represent a wide variety of music teaching and learning experiences, having taught students from birth through adults in settings including general, vocal, and instrumental music in a variety of environments. We are a diverse group of women racially and socioeconomically, and we hold a range of identity positions in terms of sexual identity and (dis)ability. Our experiences as both music teachers and learners inform our responses to Allsup's text.

Becky Marsh identifies as a white female whose passions within music live both in and outside of the formal music classroom. Having taught choral music at the high school level, served as the music director of a K-12 community-based musical theatre organization, and as an instructor of beginning class guitar and ukulele at the collegiate level, Becky approaches Allsup's Remixing the Classroom with a passion for changing the culture of music education and music teacher education to value multiple ways of musicking and welcome all types of students.

Adrienne Rodriguez is a white, middle class, early childhood and elementary general music teacher and singer. She is a classically trained musician with a very formal music education background who discovered a passion for vernacular 
and popular music after becoming a teacher. Adrienne approaches this book from the perspective of an educator who is dedicated to helping students find their unique voice and way of connecting to music, regardless of background and previous experiences.

Amy Lewis is a black, female music educator with a passion for helping students use music as a vehicle towards self-understanding. As a beginning band director, K-8 general music teacher, jazz band director, and middle school choir director, Amy views this book as an encouraging voice for an inclusive teaching environment and looks forward to how Remixing the Classroom will provoke change within our profession.

As a black bisexual female music educator who has lived most of her life below the poverty line, Latasha Thomas approaches Allsup's book reflecting on her struggles within music education and poverty as well as her time working as a band director, general music teacher, and private clarinet instructor. For Latasha, music has served as an escape from her struggles with poverty, and she is passionate about helping students explore the possibilities of music in their everyday lives.

Juliet Hess identifies as a white, female, middle class, heterosexual music educator with a (mostly invisible) disability. As a white woman who taught elementary and middle school band and choir just north of Toronto, Ontario, Canada, she identifies as conforming to the dominant music educator identity of white and female. She is deeply committed to school music education and, as such, engages Allsup's text through the lens of its possible applications to school music.

\section{Transformation}

We agree with Allsup's call for a transformation of music education, and we find that it aligns well with Jorgensen's (2003) dialectical "this with that" discourse on transforming music education.

Rather than a static event that occurs at a particular time and is immediately and virtually complete, transformation is in the process of becoming; it possesses a quality of livingness and vitality. ... As such, it seems to rise and fall against the backdrop of ordinary experience, and yet afterwards, it is clear that a profound change has occurred. Its dynamic quality makes it difficult to observe because in its unfolding there may be no single defining moment in the dynamic 
process of change. It seems to carry the seeds of change within itself and it takes time to evolve. (248)

Transforming music education, whether addressing its constituent parts or considering it as a system, is a multifaceted process. Just as Allsup describes his longing for openings in the current system of music education, we aspire to support both music educators and music teacher educators to meet the needs of a diverse and continually evolving population of learners.

Jorgensen (2003) depicts nine different images encapsulating means of transformation: modification, accommodation, integration, assimilation, inversion, synthesis, transfiguration, conversion, and renewal. In acknowledging that each of these images of transformation has limitations, and that no single image itself encapsulates transformation, she presents the notion of "this with that" (2003, 56), in which the various aspects and perspectives associated with each image are in tension with one another. Throughout his book, Allsup (2016) addresses issues of antinomy, which he defines as "a logical paradox that is drawn between two equally plausible though opposing principles, a concept whose defining characteristics cannot be understood apart from the oppositional forces that give it meaning" (72). Jorgensen's (2003) "this with that" dialectical view suggests that transforming music education may require such antinomies or possible contradictions, "one or another coming to the fore at a particular time and place as actors might move about on a stage" (56). With this consideration in mind, we use Jorgensen's models of transformation through inversion and integration to explore the permutations of the relationships between open and closed forms that Allsup presents.

Of the nine images of transformation that Jorgensen suggests, we argue that integration and inversion (and later, synthesis) better capture Allsup's visions and criticisms of music education, honoring the duality of closed and open forms in music education. Jorgensen's illustrations of transformation provide powerful images to explore Allsup's "remix." Jorgensen's other models do not as readily simultaneously maintain the importance of both "what is" and "what could be." In what follows, we point out where Allsup's recommendations correspond with inversion and where they parallel integration. We argue that, of these two forms of transformation, integration holds more promise.

Jorgensen (2003) describes the transformation of music education through 
integration as an approach in which "elements are combined in a mix that is sufficiently accommodating to enable them to coexist, but where one does not threaten the existence of another" (50). One of the appealing aspects of such a transformation is the notion that one form does not threaten the other's validity or value within the context of music education. When elements or aspects therein are combined, "a richer mixture may be created than might exist in the absence of one or other [sic.] element" (50). While attention must be paid to the combination of these elements so that one perspective does not dominate the means by which the other is judged or experienced, integration offers an option for a dialectic or, as Allsup might describe, an antinomical relationship between two disparate elements.

In inversion, conversely, "the order of things is turned upside down" (52). As its description may suggest, inversion entails a change of great magnitude as well as a reversal of values within an individual or social system. Such changes may provide greater agency to those within the system that becomes more highly valued through inversion. In considering this concept, we heed Jorgensen's concerns about transformation through inversion:

Notwithstanding its potential benefits, inversion may be restrictive or may not necessarily broaden perspectives; it simply replaces one limited view for another and relies upon a hierarchical arrangement of values that privileges some and tolerates, marginalizes, or repudiates others. (Jorgensen 2003, 52)

Ultimately, this course of action may not result in a transformation of music education so much as a shifting of the imbalance of power and privilege that exists within the current system.

Among the nine types of transformation Jorgensen describes, her framing of inversion provides a means of interpreting Allsup's overall approach to transforming music education toward an open philosophy of music education. We draw upon Jorgensen's (2003) definitions of integration to frame our response to Allsup's proposed transformation. We look to integration as a way to draw disparate elements together. This first section points to the ways in which Allsup calls for a transformation through the integration of disparate elements of music education. Heeding Jorgensen's caveats about the restrictiveness of inversion, however, the second portion of our argument points to the ways in which Allsup calls for transformation by way of inversion in a manner that is often implicit. 


\section{The Remix: Integration and Inversion}

Allsup emphasizes the distinction between open and closed forms, and he continually returns to discussion of the two forms and how they are realized within music education. He frames the majority of the descriptions of open forms positively, asserting that open forms are flexible, centered in change and creation, are often youth-driven, and involve risk and uncertainty. Individuals who embrace open forms are described as those who seek to break or reshape laws rather than set them, thus acting as border-crossers (Gaztambide-Fernández 2008) rather than gatekeepers. Teachers who choose to promote open forms in their classrooms act not as authoritarian or Master ${ }^{1}$ but as fellow adventurer alongside their students.

In stark contrast to his descriptions of open forms, Allsup often describes closed forms in a strikingly less positive way. He views closed forms as being steeped in tradition, canonical in nature, and often hierarchical, privileging a powerful or talented few (Gaztambide-Fernández 2008). Allsup states, "Closed forms represent culturally structured and norm-driven literacies, where valuations of excellence preexist an aesthetic encounter. Closed forms benefit from stability, with historically agreed-on modes of participation that are rigid and dualistic in nature (think: composer $\rightarrow$ conductor $\rightarrow$ performer $\rightarrow$ audience)" (48). An expert or Master, who bestows their knowledge on a compliant apprentice, often holds power in closed forms.

Because much of what Allsup discusses centers around the idea of open and closed forms, an understanding of how he describes and defines them is essential for analyzing Remixing the Classroom. He emphasizes the distinction between open and closed forms, continually returning to discussion of the two forms and how they are realized within music education. Allsup offers parables in chapter one-rich stories from beyond music education-to illustrate his ideas. Next, he draws upon his experience in education to think through teacher quality and expertise. Threading the work of John Dewey and Maxine Greene throughout the book, Allsup uses Dewey's notion of the school as laboratory and museum to frame chapter three. Allsup's discussion and treatment of the two forms are an important feature of the work, which we explain briefly below to contextualize our claims. We feel that his treatment of closed forms specifically throughout the 
book suggests an inversion from closed to open forms rather than the integration of the two.

\section{Both/And: The Integration of Closed and Open Forms}

Remixing the Classroom reveals exciting possibilities for music education. At times, Allsup states the need for both open and closed forms, combining these two disparate forms in a way that reflects Jorgensen's (2003) image of integration. In this section, we first discuss how Allsup defines the quality music teacher as someone who weaves and moves fluidly between both open and closed forms in their classroom. Next, we point out that through his description of an ideal school environment, Allsup works to integrate open instruction (the exploratory, experimental laboratory) and closed instruction (the traditional, historicallybased museum). We end this section by considering the ways in which the final example Allsup provides-the Orpheus Chamber Orchestra, an orchestra without a conductor-illustrates transformation via integration.

\section{Music-teacher quality and expertise}

In the second chapter, Allsup discusses music-teacher quality, calling for music teachers who can navigate both open and closed forms of music education. He states:

I define music-teacher quality as the ability and curiosity to move skillfully and knowingly within and across closed and open domains. I present a music teacher, in other words, who can teach a student to sing into a microphone as willingly and as easily as she can teach bel canto style" (39).

Allsup further provides five propositions that frame his vision of musicteacher quality and expertise:

1. Public-school music teachers are never outside the forces of replication and transformation.

2. It is the music teacher's mandate, as entrusted by her community, to know the forms of her tradition while preparing for change.

3. The music teacher grows in knowledge, skill, and disposition as she operates willingly within and across these forces and forms.

4. Quality can be measured by the degree to which a music educator can move fluidly among the forces and forms of tradition and change.

5. This manner of plasticity can be taught and thus enlarged. (46)

Marsh, Becky, Adrienne Rodriguez, Amy Lewis, Latasha Thomas-Durrell, and Juliet Hess. 2017. Seizing the "both/and" moment. Action, Criticism, and Theory for Music Education 16 (1): 101123. doi:10.22176/act16.1.101 
Allsup pairs closed and open forms by stating that the music teacher should be well-versed in tradition while working towards transformation and have the ability to "move fluidly among" (46) multiple forms. These propositions and the definition of teacher quality that Allsup poses are encouraging, as they call for a teacher who acts as a flexible expert in the classroom. This blending of new and old, and of open and closed has great potential for music education.

The music classroom as laboratory and museum

Allsup draws from Dewey's notion of the ideal school to discuss the ideal music classroom, contrasting a laboratory, which is exploratory and experimental in nature, with a museum, which is centered on heritage and conservation. Despite their seemingly opposing functions, the laboratory and the museum "should not be thought of as somehow apart from life or in contradiction with each other" (70). Allsup argues for the place of both the museum and the laboratory in music classrooms, advocating that students should have access to both tradition and innovation. "The laboratory in this sense, cannot exist without the museum. The museum, informing the work of the laboratory, is alive with innovation" (77). The presence of both the laboratory and the museum in one school environment, in other words, leads to heightened experiences in which both invention and preservation are possible.

\section{The Orpheus Chamber Orchestra}

Finally, the Orpheus Chamber Orchestra, a chamber ensemble without a conductor, illustrates a successful integration of open and closed forms. "I want to take pains to say that a tightly controlled musical form holds the possibility for agency on behalf of the executant" (135). This example highlights the possibility that even extremely traditional forms may be altered to provide opportunities for a more horizontal power structure. Allsup describes this ensemble as highly democratic (136) and one in which members collaborate and move away from the hierarchical design that is typical of professional music ensembles. The ensemble functions, Allsup contends, without abandoning the Western classical tradition in which they were trained: "Orpheus's strange hypothesis is that they can reorder the social arrangements that have come to define the very concept of an orchestra without sacrificing their dedication to the musical norms they have each come to 
love" (136). We contend the Orpheus Chamber Orchestra is an example of the successful integration of both open and closed forms.

Allsup provides evidence throughout his book that both open and closed forms have a place in music education at multiple levels. His vision of teacher quality, as well as his depiction of the school as both laboratory and museum, resonates with what Jorgensen (2000) defines as integration, "a music education curriculum where elements are combined in a mix that is sufficiently accommodating to enable them to coexist reasonably satisfactorily, but where one does not threaten the existence of another" (243). These threads throughout Remixing the Classroom indicate that perhaps Allsup sees a path that leads to the integration of both open and closed forms.

\section{Either/Or: Allsup's Implied Inversion}

While Allsup makes several explicit assertions about the need for both open and closed forms, at other times he implicitly advocates for abandoning closed forms, advocating transformation of music education through inversion. We argue that his implicit argument for inversion occurs through three mechanisms. First, despite stating a need for both open and closed forms, Allsup consistently frames open forms positively while describing closed forms negatively. This dichotomous framing makes it difficult to conceive of, or find value in, a classroom environment that is inclusive of both open and closed forms. Rather, it suggests inversion from a closed form to an open form. Second, Allsup is especially critical of the Master-apprentice model, a style of teaching that he positions firmly as a closed form. This model troubles him profoundly, leading him to call for the "demise" of the Master entirely (68). In fact, the discussion of the Master-apprentice model focuses primarily on its negative attributes, leaving no room for a more positive or integrated re-imagining of this traditional approach. Finally, we argue that the initial parables and occasionally music- or teaching-related anecdotes that Allsup introduces are polarizing in nature, urging the reader to choose a side-either closed or open forms-and that he makes clear the "correct" side is open.

\section{Polar Opposites: Open as Positive, Closed as Negative}

It is difficult to determine what Allsup believes are the positive attributes of closed forms. In his perception of the Master-apprentice teaching model, the 
apprentice must conform to the norms and expectations established by the Master or risk being viewed as unsuccessful, lacking in talent, or in the case of the music school, unmusical. Allsup regularly expresses frustration with this type of closed form. He explains in the preface of the book, "I believe that the pedagogy of closed forms-like so many economic systems around the world-is unsustainable and demands too many resources, not the least of which are time and money" (xii). Allsup sees the field of music education today as largely centered in closed forms, noting that "...the contemporary school and university, housed in a world of accountability and cross-cultural comparison, is ideally suited for all manner of closed form instruction, in which teachers traffic in musical rights and musical wrongs, saying no more than saying yes, exercising authority and demanding submission" (55). He further cautions that students who are inducted into a closed university system will struggle to unlearn that system after graduation.

The negative discussion of closed forms in a variety of contexts pervades $R e$ mixing the Classroom. Because the latter half of the book's title, Toward an Open Philosophy of Music Education, suggests Allsup's preference for open forms, this stance should not be entirely surprising. However, his call for a music teacher who can operate within both open and closed forms and his intermittent assertions that both forms are important, are contradictory to his negative accounts of closed forms and how they manifest in music education. This contradiction leads us to argue that Allsup favors a transformation to music education through the inversion of closed to open forms rather than their integration.

\section{The Master-apprentice model}

Allsup's portrayal of the Master-apprentice model of teaching reveals that he finds little inherent value in this model of closed-form instruction. Allsup describes the infusion of power and control in the Master-apprentice model-a model in which the teacher/Master dominates and the apprentice executes the work that the Master dictates. In this model, Allsup argues that authority and decision-making reside with the Master, while the apprentice has little agency in their own learning. While he acknowledges that there may be advantages to this model, such as the opportunity to learn musical traditions from an expert, Allsup 
critiques the Master-apprentice model throughout Remixing the Classroom and goes so far as to call for a "demise of the Master" (68).

Allsup's explicit call for the Master's demise challenges music education to overthrow a longstanding system, effectively proposing a transformation of music education through inversion. He urges that the Master-apprentice model be replaced by an approach in which the teacher comes alongside the student as fellow adventurer, thus removing the oppressive authority of the Master and allowing an approach that is more balanced. We worry, however, that in calling for the "demise of the Master" and the overthrow of the Master-apprentice model, Allsup misses the opportunities afforded by that model. We argue that there is, in fact, value in studying with a teacher who provides instruction that conforms to the Master-apprentice model. Rather than calling for the explicit "demise" of the Master (68), we advocate for the integration of closed forms (the Master-apprentice model) and open forms (Allsup's proposed model of teacher as fellow adventurer).

\section{Polarizing examples}

Remixing the Classroom contains few music education-based examples. Allsup explains:

In making a case for an open classroom, I am making a case for the nontransferable and the ineffable, something place-based and idiosyncratic. Each classroom is different, composed of a specific group of students, with me at this time, with these interests and talents, never to be repeated. My examples cannot be yours-not literally. (69)

Instead, Allsup uses parables to serve as examples of how open and closed forms may manifest in various contexts. Many of these examples are polarizing in nature, leading the reader to view both open forms and individuals who function within them as more desirable than their closed-from counterparts.

One such parable that portrays the Master-apprentice model as undesirable is the story of Jiro Ono, a master sushi chef with whom his apprentices consider it an honor to work in any capacity. Allsup writes that Ono assigns his apprentices single-task jobs that must be perfected before he deems them ready to progress to a new task. Although Ono's teaching strategy ultimately produces successful sushi chefs, Allsup argues that the success comes at the expense of the apprentice-a human cost. He then draws parallels between Jiro Ono's approach and the 
ways in which music teachers take up the role of the Master in their own classrooms. His critique of the Master-apprentice model in music education raises questions as to what might be lost when a student's focus is identical to that of their teacher, and what truly can be gained if teachers lack an interest in their students' unique contributions outside of the teacher's scope. Because the Master-apprentice approach thrives within a dominant/subordinate culture, Allsup argues that the human cost of the Master-apprentice model's success is too high, claims that it is unsustainable, and calls for the Master to relinquish control.

This depiction of a Master-apprentice relationship resonates within music education as well as other fields. However, not every Master-apprentice relationship functions this way. The examples provided in Remixing the Classroom portray the Master-apprentice model in an extreme, singular fashion, without acknowledgment of variation in the dynamics between the two parties. We do not disagree with a shift in hierarchical relations. We dispute, however, Allsup's urging to live in the extremes.

In contrast to examples of the closed-form Master, Allsup's illustration of Dapper Dan serves as a model of open forms personified. Dapper Dan, a Harlembased boutique owner in the 1980's, took the closed form of high fashion and opened it by altering designer clothing to create custom apparel, thus making "high-end" clothing accessible to his community-hip-hop artists, rappers, black celebrities, and athletes from Harlem. Allsup describes Dapper Dan as an innovative, community-minded individual who moved fluidly between open and closed forms (5). However, it is unclear from Allsup's description what aspects of closed forms Dapper Dan valued. We argue that this parable is an example of inversion from the closed form of high fashion, in which the Master-designer has total control, to a form that is open, where the consumers have increased agency and take on a more creative role. We argue that this parable is also a polarizing example because the closed-form fashion industry is described as undemocratic and even oppressive. Moreover, Dapper Dan's shop is described as a laboratory. While both the laboratory and the museum should function harmoniously, this parable leaves us uncertain as to what place the museum has in Dapper Dan's shop. If the "museum" in this example is the fashion industry or the traditional fashion designer, Allsup paints them in a negative light.

Allsup uses another parable, Franz Kafka's "Before the Law," to further por- 
tray the Master as a wielder of control and power (7). In this parable, Allsup introduces readers to the man from the country, who seeks admittance to the Law and the Doorkeeper, who denies the man opportunity to enter despite many attempts. Allsup draws a connection between the parable and Kingbury's ethnography of a music conservatory, specifically the Master pianist, Goldmann (Kingsbury 1988). He likens the doorkeeper to Goldmann, who praises or admonishes his students for their interpretation of the scores as they play. Allsup asserts:

I have never met a trained musician who has not encountered the cruelty and contradiction of Goldmann's way. Some supplicants, whom our profession calls the very talented, are ushered past the Law's great gate, but most of us get left outside. (8-9)

He continues by describing the experience of a young collegiate musician named Johanna who, upon entry into higher education, is told she is unmusical. He urges that, "In the face of music majors like Johanna, the university musicteacher educator is often the last hope in rekindling the light that has been extinguished by the keepers of closed forms and the upholders of traditional standards" (9). Again, the "keepers of closed forms" in this compilation of examples is only portrayed only in an antagonistic way.

This parable and the corresponding collegiate music anecdotes are troubling. We recognize and are likewise disturbed by what Allsup describes as "teacher bullying" and "acts of violence" (9). While Allsup asserts that he has never met a musician who has not experienced such cruel behaviors at the hands of their "Master", we assert that the Master does not have to embody these tyrannical traits. There exists, we argue, room for a middle ground, in which the Master may provides opportunities for the apprentice to grow and explore their interests with the guidance of a skilled expert. Allsup again leaves the reader with a vision of closed forms that is firmly unfavorable, eliciting a polarizing vision of music institutions at the collegiate level and further suggesting that music education be inverted from a closed form to an open form.

Throughout the book, Allsup offers few practical examples to move toward realizing an open philosophy that still honors aspects of closed forms. While Allsup claims to value both open and closed forms, we view the anecdotes above as examples that urge the inversion of closed forms to open forms, rather than an integration of the two. As a result of Allsup's negative framing of closed forms 
throughout the parables in the book, we lack information about what he believes to be positive attributes of closed forms that benefit or enhance the experience of the character or learner in Allsup's examples. After reading these polarizing examples and Allsup's interpretation of the Master-apprentice model, the reader is left with a sense that they must choose between open and closed forms. Allsup implicitly elevates open forms through both the negative depiction of closed forms and the lack of evidence he provides about their potential value. While we certainly see the value of open forms and their potential benefit for music education, we also see value in the use of closed forms in some contexts. Rather than firmly inverting closed forms to open forms, we seek a transformation of music education through integration of the positive attributes of both forms.

\section{Both/And: Jorgensen's “Integration” in Action}

As noted earlier, Allsup writes, "In making a case for the open classroom, I am making a case for the nontransferable and the ineffable, something place-based and idiosyncratic. ... My examples cannot be yours-not literally" (69). Upon reading this text, the lack of practical examples troubled us. Allsup asserts that a teacher should be a fellow adventurer alongside her students, learning from their experiences and sharing in the process. We believe similarly that music educators can learn from the experiences of their colleagues, finding inspiration for new approaches or adaptations of ideas that may serve them well in their respective contexts. To address Allsup's lack of practical examples, we reflected on our own practices across multiple music education settings to consider what might constitute a transformation in music education toward a more integrated practice.

\section{Becky}

To have been a student whose music education experiences fell largely within the dominant paradigm of American school music, I did not fit into the mold of the typical undergraduate music education major. I listened to my peers excitedly discuss the repertoire they were studying in private lessons, their practice schedules, and their future recital plans, while I spent the same amount of mental space and time learning and listening to and learning the entire score of whichever musical I needed to teach for the K-12 youth theatre as its music director. 
Similarly, I became painfully aware as a young high school chorus teacher ${ }^{2}$ that my values and beliefs about school music education did not align with those of the other high school music educators in the county. When many were discussing the two festival pieces they would begin following their winter concert, I was thinking through the student-suggested themes for our next event, which would be shaped largely by the solos, duets, and small group songs my students chose to prepare.

Nearly a decade later, and after the experience of teaching music in a variety of contexts, I have come to understand that these tensions I often felt are a result of being someone whose passions for music can be fulfilled through the rehearsal or performance of a beautiful choral score just as easily as by joining an on-thefly Old Time jam at the local instrument store. In my work with future music educators, I strive to provide my students with experiences or rich stories of experiences that may challenge their own, or simply broaden, their perspectives. I often find myself saying, "It's not a matter of better or worse, just different." If we believe that music truly is for everyone, which I unequivocally do, then our classrooms should encompass various ways of learning, teaching, creating, engaging with, and sharing music. Regardless of how we might define or organize each of these various ways or unique combinations therein, the integration of multiple forms and experiences in the music classroom will speak to and reach many more students than the existence of merely one over the other(s).

\section{Adrienne}

As an early childhood and elementary general music teacher, I found many ways to integrate both open and closed forms into my classroom. As a conservatorytrained musician, I have acquired substantial knowledge of traditional and classical repertoire and technique. While these skills enhance my teaching, I highly value student agency and choice in my classroom, even when working with students who are very young. I find ways to learn about my student's musical interests through student "musical identity surveys" and keeping a jar in my room where students can write down what they are currently listening to for use in class during movement activities. Popular music, as well as music representative of my students' cultural backgrounds is used regularly in my classroom activities, as are opportunities to create, compose, and improvise. 
When I begin lessons with any new private piano, guitar, or voice student, the starting place is always the same: "So you are here to take private lessons. What do you want to be able to do as a result of spending 30 minutes a week with me?" Most of my students want to "be able to play and sing songs from the radio" or "be able to be in a band with [their] friends." So, we learn how to read lead sheets, learn music without the use of traditional notation, and use technology resources to find and learn music. The private lessons I teach are very student-directed, from music selection to musical styles that we explore. However, once students have expressed what they want to know how to do, the process for teaching them is still very carefully designed and executed by me using my skills and expertise as a musician. I see private instruction as collaboration, but the power structure is not entirely horizontal. I truly believe and have experience both as a student and teacher that within the Master-apprentice model, there are opportunities for balance between Master and apprentice.

\section{Amy}

I wore many hats as a K-8 general music teacher-beginning band, jazz band, and middle school choir. I was responsible for directing the annual musical, collaborating with other music teachers within the district, creating song arrangements, and I loved every moment. My experience as a music teacher taught me the importance of welcoming student input. Remixing the Classroom validated certain choices I made as a teacher. The concept of the teacher being a fellow adventurer with the students, in particular, triggered memories of the students and me learning together. There were many moments in my middle school general music classes where my students and I would learn how to navigate new technology simultaneously. For example, my students discovered a website, Soundation.com, for creating musical loops while in the middle of our technology unit. As a team, we explored the new website, and I modified their unit assignment to include the newly discovered website. I learned something completely new alongside my students.

Learning with students allows for a more open form of teaching and challenges the concepts within the Master-apprentice model. While I understand and have experienced the benefits of an open philosophy and appreciate how Remixing the Classroom truly challenges the traditional, closed forms of teaching 
within music education, I employ a more integrated form of teaching that combines both open and closed approaches. This form of teaching allows for a balance of structure and flexibility in the classroom.

\section{Latasha}

I was not a child prodigy. In fact, I did not begin playing clarinet until the fifth grade, age 11. I did not listen to the Western canon of classical music at home, but my first memorable music moments at the piano with my grandmother taught me that music could be worthwhile and fun. Later, as a clarinet performance student, I spent a lot of time in the Master-apprentice model. Each week I had an hour-long lesson with my applied clarinet professor. I accepted the power dynamic of this model because it was all that I knew. I had little choice in the technique books from which I studied, neither did I pick out my solo material. I needed mentoring to become an innovator, but what I received were lessons on how to conform to the canon. I soon learned that the music I listened to at home and the music I was taught at school were two separate and distant worlds. Did they have to be distant worlds? Countless music educators have found ways to open this Master-apprentice model by selecting stylistically-varied repertoire that addresses students' needs, and then giving the student the power to choose which pieces she wants to play. Allowing me to choose which pieces appealed to me most would have created an instant "buy-in" to the process of learning the music and would have helped me connect with the pieces on a deeper level, thus leading to a difference in the way I performed the music. Had my teacher allowed me to select the pieces, the learning model would have changed from a completely closed Master-apprentice model to a more open, fellow adventurer, facilitator model.

\section{Juliet}

I structured this year's Ph.D. level philosophy class with a balance between exploring different philosophical perspectives and movements in music education and the use and application of theoretical frameworks in different types of academic writing. Chapter 1 of Remixing the Classroom was a required reading in week 4 of the 15-week course. Adrienne, Amy, Becky, and Latasha appreciated Allsup's call for an open education. When the editors of ACT decided to focus a 
book review issue on the book, we decided that we would like the opportunity to respond to this book that generated many conversations. Upon making that decision, the class focus shifted from a more conventional final paper based on course topics to a collaborative effort. Rather than any incarnation of the Masterapprentice model, we wrote this piece together through conversations that extended to writing and then reshaping. Toward the end of the formal class semester, Amy noted that the class had become an example of the type of education Allsup propagates. The course evolved to focus on an unexpected task and as a teacher, I became a "fellow adventurer" in the writing and responding to Allsup's text. I note, however, that while the course perhaps shifted towards an open form, there was certainly a balance between the process of writing alongside doctoral students, honoring all of the experiences that we jointly bring to this task, and sharing my own experiences from previous academic writing. The balance between this dual teacher-collaborator role became important throughout the evolving of this project. Having shared this experience in a graduate-level course, I am eager to shape my teaching in ways that provide both structure and freedom.

The examples we have shared are by no means exhaustive but are intended to portray the ways in which we each integrate closed and open forms within our various teaching contexts. Like Allsup, we yearn for a transformation of music education away from the largely closed, teacher-centered model that heavily utilizes music of the Western classical canon and its traditions. However, we find that the integration of closed and open forms encompasses a more hopeful and realistic means of transformation than the inversion that Allsup suggests.

\section{Talking Back: (Re)framing Allsup (2015)}

At the end of 2015, roughly six months prior to the publication of Remixing the Classroom: Toward an Open Philosophy of Music Education, the Music Educators Journal published a brief piece entitled “Our 'Both/And' Moment," in which Allsup reflected on the then-present state of music education. He highlighted the positive aspects of music education, noting a broader variety of music courses offered to public school music students and an increased capacity for music teachers to teach within diverse settings, but Allsup also noted longstanding issues among music education in American public schools. Addressing these 
points and other aspects of contention within music education, Allsup (2015) wrote:

So here I am, maybe like you, caught between my impatience for greater change and the satisfaction of seeing continued good work being done by my peers. Leadership, I think, is about more than pointing out what is wrong or sharing irrational fears. While the pace of change may not satisfy some and while others may bemoan the erosion of traditions they consider invariable, school and university music education is more creative and more open than ever before, and more teachers are entering the profession with a larger range of skills and the disposition to teach more imaginatively. (85)

In a nod to Estelle Jorgensen's (2003) "this with that" (56) approach, Allsup asserted, "This is our profession's both/and moment, a time of immense possibility" $(2015,85)$. Through this article, Allsup introduced a vision of music education that embraces multiple ways of playing and studying music, in which he suggested a profession focused on "both/and" practices as opposed to "either/or" practices. An "either/or" culture necessitates a choice, risking the exclusion of the option that is not chosen, while a "both/and" culture suggests the coexistence of multiple options.

Allsup's subsequent Remixing the Classroom and, specifically, the examples therein, implicitly suggest a transformation to music education that resembles Jorgensen's (2003) description of inversion, "in which the order of things is turned upside down" (52). Despite his intent to "make a case for the teacher as coauthor or reader (chapter 1), a flexible expert who moves comfortably within closed and open arenas (chapter 2), a laboratory facilitator (chapter 3), and a fellow adventurer (chapter 4)" (2016, 11-12), Allsup implies that closed forms lack a place in his vision of music education or that they serve only as a means to understanding open forms. This argument not only contradicts his 2015 call for our profession to embrace its "both/and moment" but also belies his 2016 description of the quality music teacher who moves fluidly between both closed and open forms.

We envision the first step toward transforming music education as Jorgensen's (2003) concept of integration, in which "elements are combined in a mix that is sufficiently accommodating to enable them to coexist, but where one does not threaten the existence of another" (50). Being careful to push beyond what Charlene Morton (1994) calls an "add and stir" approach, integration may serve 
as the practical means through which music education might grow and evolve to include both closed and open forms, ultimately creating a new model of music education. We use Jorgensen's (2003) image of transformation through synthesis, "the blending or melding of opposites into a new entity" (52), to illustrate this concept:

The paradoxical nature of synthesis and the underlying tension between thesis and antithesis imply the possibility of an even larger idea, concept, or thing that might encompass both, where the underlying paradoxes and dialectics can be resolved or accommodated in some way, and aspects of the two can be melded. Synthesis accomplishes a resolution of conflict or tension by offering a new alternative. (52)

We assert that integration as a means to eventual synthesis might allow for music educators and music teacher educators to seize the "both/and moment" Allsup (2015) first described, as opposed to the inversion he implies throughout Remixing the Classroom (2016).

Through the examples he put forth to illustrate "both/and" practices within music education, Allsup (2015) described how the integration of closed and open forms might result in the creation of new entities:

But my hunch is that a band director who teaches songwriting will begin to teach band differently. A theorist who coaches a popular music ensemble will begin to teach theory differently, too. Categories may blur, but rather than seeing loss, we will invent forms of knowledge and new ways of teaching. Music education will be at one with our times. And we will listen, and keep listening, for new frequencies. (86)

Calling for the transformation of music education, Allsup (2016) refers to the emergence or creation of new "frequencies" (33). If we draw upon Jorgensen's "this with that" dialectical view, which suggests that transforming music education may require what Allsup (2016) calls "antinomies" (72), then the presence of both closed and open forms is essential for the creation of new frequencies. Let us, then, strive to listen for new frequencies that emerge as a result of open and closed forms functioning reciprocally, as opposed to those that sound only at the expense of closed forms.

\section{About the Authors}


Becky Marsh is a Ph.D. student and graduate teaching assistant in music education at Michigan State University. Prior to her graduate work, Becky served as a high school chorus teacher in North Carolina. She has taught beginning guitar, ukulele and music courses for elementary education majors, supervised student teachers, and assisted in introductory music education and choral methods courses. Becky holds Bachelors and Masters degrees in Music Education as well as a Post-Baccalaureate Certificate in Music Theory from the University of North Carolina at Greensboro. Her research interests include music teacher identity and socialization, pre-service teachers' field experiences, and creative musicianship in the ensemble setting.

Adrienne Rodriguez is a Ph.D. student and graduate assistant in music education at Michigan State University, where she supervises student teachers, teaches early childhood music classes for parents and children, and assists with elementary and early childhood music methods courses. She previously taught elementary general music, early childhood music, and private instrumental and vocal lessons in Florida. She holds a Bachelors of Music Education degree from the Eastman School of Music and a Masters in Music Education from The University of Miami. Her research interests include early childhood music, musical home environment, and musical parenting.

Amy Lewis is a Ph.D. music education student and graduate assistant at Michigan State University, where she teaches secondary general music methods, supervises student teachers and holds multiple leadership positions within the Graduate Employees Union. Previously, she taught K-8 general music, beginning band, middle school choir, and jazz band in Des Plaines, Illinois and was named the 2015 Illinois Education Association Teacher of the Year. She holds a Bachelors of Music Education degree from DePaul University and Masters of Arts in Teacher Leadership from Concordia University. Her research interests include unionism within music education, music education and social justice, and inclusive learning and teaching environments.

Latasha Thomas-Durrell is currently a Ph.D. student and graduate teaching assistant in music education at Michigan State University, where she teaches songwriting and supervises student teachers. Her research interests include LGBTQ issues in music education and music education and social justice. Thomas has held teaching positions in Tennessee, where she taught general music and band classes. She holds a MM in Music Performance from the University of Central Arkansas, a MM in Music Education from the University of North Carolina at Greensboro, and a BM in Music Education from the University of Tennessee at Martin.

Juliet Hess is an assistant professor of music education at Michigan State University, where she teaches secondary general methods in music education, principles

Marsh, Becky, Adrienne Rodriguez, Amy Lewis, Latasha Thomas-Durrell, and Juliet Hess. 2017. Seizing the "both/and" moment. Action, Criticism, and Theory for Music Education 16 (1): 101123. doi:10.22176/act16.1.101 
in music education, and philosophy and sociology of music education. Juliet received her Ph. D. in Sociology of Education from the Ontario Institute for Studies in Education at the University of Toronto. She previously taught elementary and middle school vocal, instrumental, and "world" music at a public school in the Greater Toronto Area. Her research interests include anti-oppression education, activism in music and music education, music education for social justice, and the question of ethics in world music study.

\section{References}

Allsup, Randall Everett. 2015. Another perspective: Our "Both/And" moment. Music Educators Journal 102 (2): 85-6.

Allsup, Randall Everett. 2016. Remixing the classroom: Toward an open philosophy of music education. Bloomington: Indiana University Press.

Gaztambide-Fernández, Rubén. 2008. The artist in society: Understandings, expectations, and curriculum implications. Curriculum Inquiry 38 (3): 23365.

Jorgensen, Estelle R. 2003. Transforming music education. Bloomington: Indiana University Press.

Jorgensen, Estelle R. 2000. What does it mean to transform education? Philosophy of Education Archive: 242-52. Retrieved from http://ojs.ed.uiuc.edu/index.php/pes/article/view/1978/684 on February 8, 2017.

Kingsbury, Henry. 1988. Music, talent, and performance: A conservatory cultural system. Philadelphia: Temple University Press.

Koza, Julia Eklund. 2008. Listening for whiteness: Hearing racial politics in undergraduate school music. Philosophy of Music Education Review 16 (2): $145-55$.

Morton, Charlene. 1994. Feminist theory and the displaced music curriculum: Beyond the "add and stir" projects. Philosophy of Music Education Review 2 (2): $106-21$.

Nettl, Bruno. 1994. Heartland excursions: Ethnomusicological reflections on schools of music. Urbana, IL: University of Illinois Press.

Marsh, Becky, Adrienne Rodriguez, Amy Lewis, Latasha Thomas-Durrell, and Juliet Hess. 2017. Seizing the "both/and" moment. Action, Criticism, and Theory for Music Education 16 (1): 101123. doi:10.22176/act16.1.101 


\section{Notes}

${ }^{1}$ We capitalize "Master" here because Allsup consistently capitalizes Master, emphasizing the power relations between Master and apprentice. In envisioning more horizontal relationships between teacher and student, we do not necessarily align with this capitalization.

2 I intentionally use the phrase "chorus teacher" as opposed to the commonly used "choral director" because I believe the latter insinuates a director-centric approach to the choral ensemble, which does not reflect my beliefs about the role of the teacher in the classroom or my practices when working with choral ensembles. 